\title{
Expression of the Sodium lodide Symporter and Thyroglobulin Genes Are Reduced in Papillary Thyroid Cancer
}

\author{
Matthew D. Ringel, M.D., Jeffery Anderson, B.S., Suzikelli L. Souza, M.D., Henry B. Burch, M.D., \\ Marcos Tambascia, M.D., Craig D. Shriver, M.D., R. Michael Tuttle M.D. \\ Departments of Clinical Investigation (JA), Medicine (HBB), and Surgery (CDS), Walter Reed Army \\ Medical Center, Washington, DC; Department of Medicine, Washington Hospital Center/Medstar Research \\ Institute (MDR, SLS), Washington, DC; Department of Medicine, University of Campinas (SLS, MT), Sao \\ Paulo, Brazil; and Endocrinology Service, Memorial Sloan-Kettering Cancer Center (RMT), New York
}

\begin{abstract}
Altered expression of the gene encoding the sodium iodine symporter (NIS) may be an important factor that leads to the reduced iodine accumulation characteristic of most benign and malignant thyroid nodules. Both up- and down-regulation of NIS gene expression have been reported in thyroid cancer using several different methods. The goal of the present study was to accurately identify alterations in NIS gene expression in benign and malignant thyroid nodules using an accurate real-time quantitative RT-PCR assay system. Total RNA was prepared from 18 benign thyroid nodules, 20 papillary thyroid cancers, and 23 normal thyroid samples from 38 subjects. Quantitative RT-PCR was used to measure NIS and thyroglobulin (TG) mRNA expression in normal thyroid tissue and in each nodular tissue sample.Papillary thyroid cancer samples had significantly lower NIS mRNA expression $(72 \pm 41$ picogram equivalents [pg Eq]), than did benign nodules $(829 \pm 385 \mathrm{pg} \mathrm{Eq})$, or normal tissues $(1907 \pm$ $868 \mathrm{pg} \mathrm{Eq}, P=0.04)$. Most important, in the paired samples, NIS gene expression was decreased in each papillary thyroid cancer compared with normal tissue $(69 \%$ median decrease; range, $40-96 \% ; P=$ .013). Eleven of the 12 benign nodules also demonstrated lower NIS gene expression than the normal tissue (49\% decrease; range, $2-96 \% ; P=.04$ ). Analysis of the paired samples demonstrated that $\mathrm{Tg}$ mRNA expression was significantly lower in each of
\end{abstract}

Copyright (C) 2001 by The United States and Canadian Academy of Pathology, Inc.

VOL. 14, NO. 4, P. 289, 2001 Printed in the U.S.A

Date of acceptance: December 22, 2000.

This work was funded in part by a grant provided by the Thyroid Research Advisory Council (BASF/Knoll Pharmaceuticals) to M.D.R.

This work was presented in part at the 1999 Annual Meeting of the American Thyroid Association, Palm Beach, Florida, September 29-October 3.

Address reprint requests to: R. Michael Tuttle, M.D., Endocrinology Service, Memorial Sloan Kettering Cancer Center, Box 419 (H-715), 1275 York Avenue, New York, New York 10021; e-mail: rmtuttle@hotmail.com; fax: 212-794-5821. the thyroid cancer samples than in corresponding normal tissue $(759 \pm 245$ pg Eq $v s .1854 \pm 542$ pg $\mathrm{Eq}, P=.03)$. We have demonstrated a significant decrement in NIS gene expression in all papillary thyroid cancers and in over $90 \%$ of benign nodules examined compared with adjacent normal thyroid tissue, using a highly accurate quantitative RT-PCR technique. Similarly, thyroid cancers demonstrated significantly lower TG mRNA expression than corresponding normal thyroid. Reduced NIS expression may be an important factor in the impairment of iodine-concentrating ability of neoplastic thyroid tissues.

KEY WORDS: Quantitative RT-PCR, Sodium iodide symporter, Thyroid cancer, Thyroid nodules.

Mod Pathol 2001;14(4):289-296

Although the presence of a functional iodine transport protein on the basolateral membrane of thyroid follicular cells has been demonstrated using both in vitro and in vivo systems for many years, the precise molecular structure of the sodium iodide symporter (NIS) was only recently characterized $(1,2)$. Cloning of the cDNA for NIS and development of anti-NIS antibodies has permitted investigation of factors that influence NIS expression and function at both the mRNA and protein level (3-14).

In addition to the numerous studies evaluating NIS gene expression in cell culture and animal models $(3,6,15-18)$, several investigators have examined human clinical thyroid tissue samples obtained at the time of thyroidectomy $(4,8,9,17,19$, 20). As expected, an increase in NIS expression has been demonstrated in thyroid glands obtained from patients with Graves' disease and in autonomously functioning thyroid nodules $(4,8,9,17,19$, 20). Moreover, recent studies have confirmed that 
NIS gene expression is generally lower in nonfunctioning benign thyroid nodules than in surrounding normal thyroid tissue (4). However, the level of NIS expression in malignant thyroid nodules is less certain.

Saito et al. (21) reported increased NIS mRNA expression in papillary thyroid cancer specimens compared with normal thyroid samples by Northern blot analysis. Significantly, in this particular patient population, NIS mRNA expression was higher in the papillary thyroid cancer samples than in adjacent normal thyroid obtained from the same individual in three of four cases. However, these data have not been replicated in several other small studies in which a variety of methods were used to analyze expression of NIS protein or mRNA $(5,8$, 19, 22, 23).

Specifically, reduced immunohistochemical staining for NIS protein in papillary cancer samples was seen by both Jhiang et al. (8) and Calliou et al. (19) using two different anti-NIS antibodies. In addition, Smanik et al. (22) reported decreased NIS mRNA expression by Northern blot and by nonquantitative reverse-transcription polymerase chain reaction (RTPCR) in two papillary thyroid cancers.

Ryu et al. developed a competitive RT-PCR assay to amplify and measure NIS mRNA levels from eight papillary thyroid cancer samples (5). When taken together, these papillary carcinomas appeared to have lower NIS mRNA expression than unpaired normal thyroid tissue, although this difference did not reach statistical significance. Significantly, analysis of three paired samples revealed reduced NIS gene expression in the cancer tissues compared with adjacent normal thyroid tissue, results that are disparate from those reported by Saito et al. (21).

Lazar et al. (23) published results of a real-time quantitative RT-PCR assay for NIS mRNA in which they examined 38 papillary thyroid cancer samples (five paired samples). Overall, the thyroid cancer specimens demonstrated a decrease in NIS expression compared with unpaired normal thyroid tissue (median decline, 100-fold; range, 10- to 1200-fold reduction). However, the importance of studying paired samples is exemplified by three subjects in whom the NIS mRNA levels in the thyroid cancer were lower than that of the adjacent normal tissue but overlapped significantly with the levels seen in unpaired normal thyroid tissue.

Lazar et al. (23) extended the analysis to include other thyroid-specific transcripts, such as thyroid peroxidase (TPO), TSH receptor (TSH-R), and thyroglobulin (TG). A decrease in both TSH-R and TG was seen in the thyroid cancer samples compared with the case of unmatched normal thyroid tissues $(n=5)$. In thyroid cancer tissues, a positive correlation was found between expression of NIS, TPO,
TG, and TSH receptor mRNAs. No significant differences in TG, TPO, or TSH-R expression were seen between the normal thyroid samples and benign nodular thyroid tissue. These findings are consistent with previous reports that have examined thyroid-specific transcript expression in thyroid tumors using immunohistochemistry or RT-PCR (24-26).

A recent study by Park et al. (27) examined NIS, TG, and TSH-R expression in 23 cases of papillary thyroid carcinomas and 5 unpaired normal thyroid tissues. Using semiquantitative RT-PCR and RNase protection assay, NIS expression varied from undetectable to abundantly present and appeared to be lower in thyroid cancer samples than in the normal control thyroid tissues. In thyroid cancer samples, NIS expression was significantly correlated with TSH-R expression but not with TG expression. Interestingly, no correlation in NIS mRNA expression was seen in seven paired samples of primary tumor and lymph node metastases.

Our objective was to use real-time, quantitative RT-PCR to accurately determine NIS and TG mRNA levels in normal, benign, and malignant thyroid tissue in a larger number of subjects in whom both nodular and normal tissue were available.

\section{MATERIALS AND METHODS}

\section{Thyroid Samples}

Thyroid samples from both the index nodule and grossly normal-appearing thyroid tissue surrounding the nodule were obtained at the time of clinically indicated thyroidectomy after obtaining informed consent under a protocol approved by the human use institutional review board of the Walter Reed Army Medical Center, Washington, DC. Selection of appropriate tissue for snap freezing was based on frozen-section analysis of the nodule and of normal tissue at the time of tissue collection. All benign and malignant nodule samples contained at least $75 \%$ neoplastic cells. These samples included 18 benign nodules, 20 papillary thyroid cancers, and corresponding paired normal tissues in 23 of these subjects.

Histologically verified normal thyroid tissue was obtained from a clinically euthyroid subject undergoing thyroidectomy for a solitary benign thyroid nodule after obtaining informed consent. Total RNA extracted from this sample was used to prepare a standard curve against which all unknown samples were compared.

\section{RNA Extraction}

Each sample was snap frozen in liquid nitrogen within 15 minutes of collection and stored at $-70^{\circ} \mathrm{C}$ 
pending RNA recovery. Total RNA was recovered using TRIzol extraction according to the manufacturer's suggested protocol (Gibco BRL, Life Technologies, Gaithersburg, MD).

\section{Assay Quantitation}

A standard concentration curve was prepared from a single normal thyroid immediately frozen in liquid nitrogen at the time of thyroidectomy as previously described (28). RNA was extracted as described above and quantified by absorptiometry (Beckman DU 65 Spectrophotometer, Fullerton, CA). Dilutions were made to produce a calibration curve ranging from 0.08 to $50 \mathrm{ng}$ of total thyroid RNA per tube. NIS and TG mRNA were amplified for each of the standards using the reaction conditions described below.

RT-PCR standard curves were created using the threshold cycle, defined as the point at which each reaction reaches the logarithmic portion of the PCR curve. The cycle number at which a reaction reaches this point in the curve is directly proportional to the amount of cDNA template in the PCR reaction. Thus, this relationship allows for the creation of linear calibration curves over a wide concentration range. Standards and subject samples were assayed in duplicate.

\section{cDNA Synthesis}

For each transcript of interest, $500 \mathrm{ng}$ of total RNA were reverse transcribed to cDNA using random hexamer primers per the manufacturer's recommendations (ABI, Foster City, CA) in a total volume of $10 \mu \mathrm{L}$. Final reaction concentrations were as follows: $1 \times$ TaqMan buffer, $5.5 \mathrm{mmol} / \mathrm{L} \mathrm{MgCl}, 500$ $\mu \mathrm{mol} / \mathrm{L}$ each dNTP, $2.5 \mu \mathrm{mol} / \mathrm{L}$ random hexamer, $0.4 \mathrm{U} / \mu \mathrm{L}(400 \mathrm{kU} / \mathrm{L})$ RNase inhibitor, $1.25 \mathrm{U} / \mu \mathrm{L}$ Multiscribe Reverse Transcriptase (1250 kU/L). Reverse transcription was performed at $37^{\circ} \mathrm{C}$ for 10 minutes, at $48^{\circ} \mathrm{C}$ for 30 minutes, and at $95^{\circ} \mathrm{C}$ for 5 minutes. The entire $10-\mu \mathrm{L}$ aliquot of synthesized cDNA served as template for PCR amplification.

\section{Quantitative PCR}

Quantitative RT-PCR was performed in 96-well plates by using either TG- or NIS-specific primers and probe with the ABI PRISM 7700 Sequence Detection System. Intron-spanning NIS-specific primers were designed to amplify a 141-bp product from bp 1267 to bp 1407 in the cDNA sequence (GenBank accession number U66088) as follows: sense, 5'-ACACTGACTGCGACCCTCTCCT-3'; antisense, 5'-TGCTGAGGGTGCCACTGTAA-3'. The sequence of the internal antisense 23-mer oligoprobe was as follows: 5'-FAMCGAAGATCTGCCTGGAGTCCCCG-TAMRA-3' (bp 1346-1368). Thyroglobulin-specific primers that spanned a 1.5-kb intron were designed to amplify an 87-bp product from bp 262 to bp 348 in the cDNA sequence as follows:

Sense, 5'-GTGCCAACGGCAGTGAAGT-3'; antisense, 5'-TCTGCTGTTTCTGTAGCTGACAAA-3'; oligoprobe, 5'-FAM-ACAGACAAGCCACA GGCCGTCCT-TAMRA-3' (28). To identify amplification of any contaminating genomic DNA, all PCR products were visualized by agarose gel electrophoresis followed by ethidium bromide staining.

Each sample was assayed in duplicate in a total volume of $50 \mu \mathrm{L}$. Final reaction conditions were as follows: $1 \times$ TaqMan buffer A; $0.5 \mathrm{~g} / \mathrm{L}$ gelatin; 0.1 $\mathrm{mL} / \mathrm{L}$ Tween 20; $80 \mathrm{~mL} / \mathrm{L}$ glycerol; $5.5 \mathrm{mmol} / \mathrm{L}$ $\mathrm{MgCl} ; 200 \mu \mathrm{mol} / \mathrm{L}$ dATP, dCTP, and dGTP; 400 $\mu \mathrm{mol} / \mathrm{L}$ dUTP; $200 \mathrm{nmol} / \mathrm{L}$ of each primer; 100 nmol/L TaqMan oligoprobe; $10 \mathrm{kU} / \mathrm{L}$ AmpErase UNG; $25 \mathrm{kU} / \mathrm{L}$ AmpliTaq Gold. The cycling conditions included an initial phase of 2 minutes at $50^{\circ} \mathrm{C}$, followed by 10 minutes at $95^{\circ} \mathrm{C}$ for AmpErase, then 40 cycles of 15 seconds each at $95^{\circ} \mathrm{C}$, and 1 minute at $60^{\circ} \mathrm{C}$. Samples in which reverse transcriptase was omitted or template were omitted were included in each reaction to evaluate for assay contamination.

\section{PCR Product Characterization}

In addition to quantitative analysis using the $\mathrm{ABI}$ PRISM 7700 Sequence Detection System (ABI, Foster City, CA), all RT-PCR products were analyzed by electrophoresis through 3\% agarose gels followed by ethidium bromide staining to ensure amplification of the appropriately sized product. To further confirm the identity of the product, forward and reverse strands of several of the RT-PCR products were sequenced with the PRISM Ready Reaction DyeDeoxy Terminator Cycle Sequencing Kit (PE/ $\mathrm{ABI}$ ) using a denaturing gel of $4.75 \%$ acrylamide, 8.3 $\mathrm{M}$ urea, and $1 \times \mathrm{TBE}\left(2500 \mathrm{~V}, 30^{\circ} \mathrm{C}, 10 \mathrm{~h}\right)$ on the PE/ABI 373 DNA Sequencer.

\section{Data Presentation and Statistical Analysis}

Measured amounts of NIS and TG mRNA are presented as picogram equivalents (pg Eq). One pg Eq is equal to the amount of NIS (or TG) mRNA present in 1 pg of total thyroid RNA obtained from a single normal thyroid gland. Because the calibration curve was prepared from dilutions of known amounts of total RNA from a normal thyroid, all measured values can be expressed relative to the amount of NIS (or TG) present in 1 pg of normal thyroid RNA.

All data is expressed as mean \pm SEM. Differences between multiple groups were analyzed using analysis of variance. Paired analysis was performed by paired $t$-test analysis (SPSS; SPSS Inc, Chicago, IL). A $P$ value $<.05$ was considered significant. 


\section{RESULTS}

Visualization and Confirmation of RT-PCR Products

The appropriately sized 141-bp NIS and 87-bp TG cDNA RT-PCR product was visible on agarose gel electrophoresis for each standard concentration. Sequencing of the PCR product confirmed the expected NIS or TG cDNA sequence as appropriate. Visual inspection of the PCR products by gel electrophoresis confirmed the appropriate approximate size for each of the unknown samples. Negative controls did not demonstrate amplified product.

\section{Standard Curve}

The standard curve of the duplicate assay values demonstrated a strong linear relationship with $r>$ 0.99 for each transcript (See Figure 1). The intraassay coefficient of variance for the threshold cycle of the calibrators run in duplicate was consistently $<2 \%$. Negative controls omitting either reverse transcriptase or cDNA template consistently failed to demonstrate detectable PCR product at 40 cycles.

\section{NIS mRNA Expression}

Results of NIS quantification for each of the individual samples are shown overlaid on the standard curve in Figure 1. Each sample had detectable amounts of NIS mRNA ranging from 0.05 to $1100 \mathrm{pg}$ Eq of NIS mRNA per picogram of normal thyroid RNA. The lowest value was seen in a papillary thyroid cancer sample that approached the lower limits of reproducible detection in this assay.

As a group, papillary cancer specimens had strikingly lower NIS mRNA levels than the unpaired



FIGURE 1. Calibration curve for sodium iodine symporter mRNA (gray circles) overlaid with individual sample results (black circles) using the TaqMan PCR analysis. The standard curve is generated by plotting the log of the input amount of normal-thyroid RNA (nanograms total-thyroid RNA, $\mathrm{x}$ axis) versus the threshold cycle (y axis) as described in materials and methods. normal control nodules (77 vs. 1907 pg Eq, $P=.04$; see Figure 2). NIS expression in benign nodules, at $826 \mathrm{pg} \mathrm{Eq}$, was intermediate between the normal tissue and the papillary cancers.

A surprisingly wide range of NIS mRNA expression was identified in both the normal samples (3.6 to $12,939 \mathrm{pg} \mathrm{Eq})$ and the benign-nodule samples (0.2 to $5486 \mathrm{pg} \mathrm{Eq}$ ). The papillary cancer samples displayed a much lower and more restricted range of NIS mRNA expression ( 0.16 to $133 \mathrm{pg}$ Eq). These wide ranges resulted in considerable overlap between normal, benign, and papillary cancer samples among different subjects.

\section{NIS Expression in Papillary Cancer Paired Samples}

We next analyzed NIS expression in the 11 thyroid cancer patients in whom samples from both malignant and adjacent normal thyroid tissue were available. In this paired-sample analysis, the normal tissue from the same patient serves as a control for TSH level and other NIS regulatory factors. Each of the 11 cancers showed a remarkable decrease in NIS expression when compared with adjacent tissue (mean decrease, $69 \%$; range, $40-96 \%, P=.013$ ). See Figure 3.

\section{NIS Expression in Benign-Nodule Paired Samples}

A similar analysis was performed in 12 paired samples from subjects with benign thyroid disease. NIS expression was significantly lower in benign nodules than in their corresponding normal tissue $(P=0.04$; See Figure 4). However, two samples showed a $<5 \%$ decrease, and one sample had a $95 \%$ increase in NIS expression. Excluding the single nodule with increased expression, the mean decrease in NIS expression was $49 \%$, with a range of $2-96 \%$. We suspect that the single nodule showing increased NIS expression is likely to have been an



FIGURE 2. Sodium iodine symporter (NIS) mRNA expression (in ng Eq) was significantly higher in normal tissues (1907 \pm 868 picogram equivalents [pg Eq] NIS), than in benign nodules $(829 \pm 385 \mathrm{pg}$ Eq NIS), or papillary cancer specimens $(72 \pm 41 \mathrm{pg}$ Eq NIS, $P=.04)$. 


\section{Paired Cancer Samples $(n=11)$}



FIGURE 3. Paired samples of normal tissue (black circles) and papillary cancer samples (gray circles) from 11 individual subjects. Sodium iodine symporter mRNA expression (log scale, y axis) is significantly decreased in each of the papillary thyroid cancer specimens relative to its normal control (69\% decrease; range, 40-96\%; $P=.013)$.



FIGURE 4. Paired samples of normal tissue (black circles) and benign thyroid nodules (gray circles) from 12 individual subjects. Eleven of the 12 benign nodules demonstrated less sodium iodine symporter (NIS) expression (log scale, y axis) than the surrounding normal tissue $(49 \%$ decrease; range, $2-96 \% ; P=.04$ ). Two subjects demonstrated a $<5 \%$ decrease in NIS mRNA expression (denoted by asterisks). One subject demonstrated a $94 \%$ increase in NIS mRNA expression in the benign nodule compared with its normal control tissue (open arrow).

autonomously functioning nodule, but no clinical information was available on this patient.

\section{TG mRNA Expression}

Thyroglobulin was also detectable in each sample and ranged from 2 to $38,700 \mathrm{pg}$ Eq TG mRNA. In the unpaired analysis, thyroglobulin expression was similar in normal thyroid samples $(1100 \pm 267 \mathrm{pg}$ Eq) and cancers (1106 $\pm 190 \mathrm{pg} \mathrm{Eq})$ and was somewhat higher in benign nodules $(2618 \pm 267 \mathrm{pg}$ Eq; $P$ $=.15$ by ANOVA).

Analysis of the paired samples demonstrated that Tg mRNA expression was significantly lower in each of the thyroid cancer samples than in corresponding normal tissue $(759 \pm 245$ pg Eq $v s .1854 \pm 542$ pg Eq, $P=.03$ ).

Thyroglobulin mRNA expression was higher in $6 / 7$ benign nodules than in the corresponding normal thyroid tissue, although this difference did not achieve statistical significance $(1800 \pm 375$ pg Eq for benign nodules $v s .1086 \pm 543 \mathrm{pg}$ Eq for normal thyroid tissue, $P=.3$ ).

As with NIS expression, a rather wide range of values was seen in the normal thyroid tissue samples (13-3678 pg Eq) and in the benign nodules (8-17,300 pg Eq). Unlike NIS, the cancer samples did not demonstrate a more narrow range of TG values than normal tissue (2-2800 pg Eq).

\section{Correlation of NIS and TG mRNA Expression}

Because of the wide range of values for both NIS and TG in the normal thyroid tissue and the benign nodular tissue, we were concerned that a procedural error resulting in degradation of the mRNA could have falsely lowered some of our results. If this were the case, subjects with the lowest levels of NIS expression should also have the lowest levels of TG expression. Samples demonstrating high TG levels with low NIS levels (or the converse) would argue against nonspecific RNA degradation being responsible for the low-level transcript expression seen in many of the samples.

The correlation of NIS and TG mRNA expression is depicted in Figure 5. Although a statistically significant correlation is present $(r=0.57, P=.014)$, a wide range of TG expression is seen with the lowest levels of NIS expression. The highest NIS value $(12,939 \mathrm{pg} \mathrm{Eq})$ is not shown on the graph but correlates with a midrange TG value of $909 \mathrm{pg}$ Eq. Similarly, the highest level of TG expression $(38,700$ pg Eq) correlates with $4.4 \mathrm{pg}$ Eq of NIS mRNA.

When examined based on thyroid histology, there was no significant correlation between TG and NIS expression in normal thyroid samples $(r=$ $0.32)$ or in benign nodules $(r=0.17)$. There was a strong trend toward a significant association between TG and NIS expression in the cancer samples $(r=0.77, P=.07)$.

\section{DISCUSSION}

In the present study, we have shown that NIS mRNA expression is markedly reduced in papillary thyroid cancer compared with adjacent normal thy- 


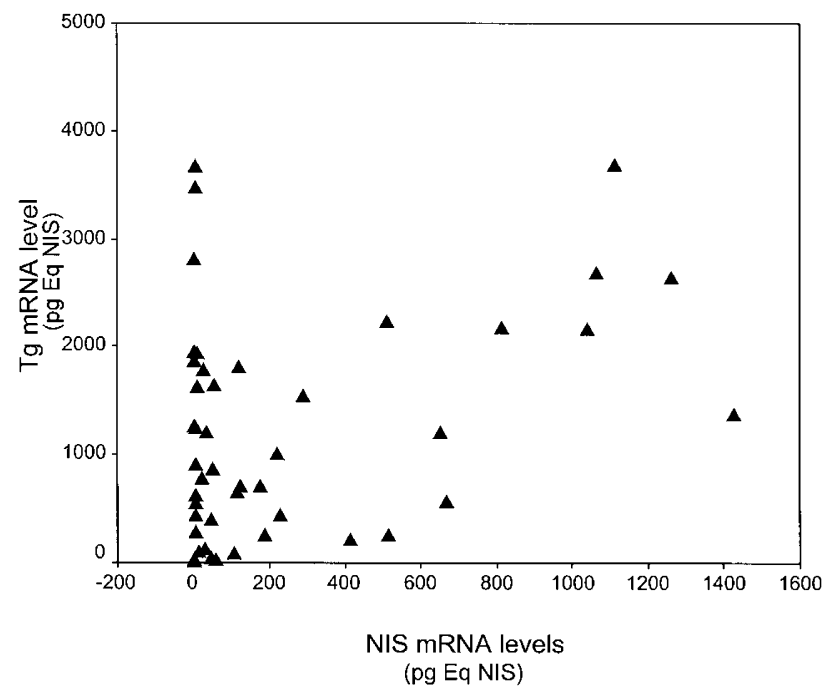

FIGURE 5. A significant correlation between thyroglobulin (TG) and sodium iodine symporter (NIS) mRNA expression is seen when all samples are analyzed $(r=0.57, P=.014)$. Individual samples with TG values from 0 to 5000 and NIS values from 0 to 1600 are shown in this scatterplot. A wide range of TG expression (up to nearly 4000 picogram equivalents [pg Eq]) is seen with the lowest levels of NIS expression. The highest value of NIS (12,939 pg Eq) correlates with a TG of 909 pg Eq (data point not shown on the graph). The highest level of TG expression $(38,700 \mathrm{pg}$ Eq) correlates with $4.4 \mathrm{pg}$ Eq of NIS mRNA (data point not shown on the graph).

roid tissue when analyzed by quantitative RT-PCR. The reduced levels of NIS gene expression were demonstrated in all 12 papillary cancers evaluated, suggesting a pattern that may be characteristic of this type of cancer. These findings are consistent with the results of smaller studies of paired samples recently published $(5,23)$ but differ substantially from the early report by Saito et al. (21). The reasons for the differences in these findings are not clear but may relate to sample preparation, use of different techniques for quantitation, or to differences in tumor histology or infiltration of adjacent thyroid tissue with lymphocytes.

Factors other than NIS gene expression could also result in reduced iodine uptake and organification in thyroid cancers. These include but are not limited to loss of thyroid peroxidase activity or expression, altered processing or splicing of NIS protein, or improper membrane targeting of NIS. Thus, a normal or elevated level of NIS mRNA may not correlate with increased iodine uptake (particularly in a malignancy); however, a reduction in expression of NIS mRNA or protein would likely correlate with reduced iodine uptake.

NIS gene expression was also generally decreased in benign thyroid nodules compared with adjacent normal tissue, but to a lesser degree than the papillary thyroid cancer tissue. The single benign nodule with increased NIS expression relative to the adjacent normal tissue may have represented an autonomously functioning nodule, although clini- cal information was not available. This conjecture is consistent with the finding that benign nodules with increased radioactive iodine concentration have high levels of NIS mRNA expression (4). Because benign thyroid nodules are known to have a wide range of radioactive iodine-concentrating abilities relative to surrounding normal thyroid tissue on nuclear medicine scans, it is not surprising that NIS mRNA expression could range from increased (hot nodules) to minimally decreased (warm nodules) to markedly decreased (cold nodules).

Thyroglobulin mRNA was detectable in each of the samples. Unpaired analysis demonstrated little difference between normal thyroid tissue, nodular thyroid tissue, and thyroid cancer. However, the paired analysis clearly demonstrated a significant decrease in TG expression in thyroid cancers compared with corresponding normal thyroid tissue $(759 \pm 245$ pg Eq vs. $1854 \pm 542$ pg Eq, $P=.03)$. These findings are consistent with those reported by quantitative RT-PCR, qualitative RT-PCR, and immunohistochemical analysis (23-26).

The range of NIS mRNA expression was surprisingly wide in our 23 normal samples (3.6 to 12,939 pg Eq). This range of NIS mRNA expression in our group of 23 normal samples appears to be wider than that reported previously using quantitative RT-PCR. Ryu et al. (5) reported a range of 0.096 to $62 \times 10^{-21}$ mol NIS mRNA in 7 normal thyroid samples examined. Similarly, Lazar et al. (23) demonstrated only a one- to threefold difference relative to a single standard normal sample in the measurement of NIS mRNA in five normal thyroid samples. The reasons for these differences in the variability of baseline NIS mRNA expression in normal thyroid tissue between these previous studies and our current work is not certain. However, both of these earlier studies examined only a small number of normal thyroid tissue samples compared with the case of the present study.

The wide variability in NIS expression in normal tissues could be due to several technical factors. Of primary concern would be RNA degradation at some point in the tissue collection, sample freezing, fresh-frozen tissue storage, or in the RNA recovery and amplification steps. The finding of a wide range of TG values in samples with the lowest NIS measurements argues strongly against a generalized degradation of RNA in these samples (See Figure 5). Because the TG and NIS messages appear to be expressed in similar quantities, a significant degradation of the NIS message without a concurrent loss of TG message seems very unlikely. Therefore, it appears that factors other than nonspecific degradation of RNA must be responsible for the wide range of NIS expression seen in the normal tissues.

Other possible technical reasons for the NIS results in the normal tissues could include differences 
in the length of time RNA was stored after recovery as well as nonspecific amplification of contaminating DNA. RNA storage time is unlikely to account for the variability of NIS mRNA expression because all samples underwent RNA recovery at the same time and were stored together at $-70^{\circ} \mathrm{C}$ for $<2$ months before RT-PCR analysis. Assay interference with contaminating DNA would have been detected as an inappropriately large intron-spanning PCR product on the agarose gel electrophoresis. Furthermore, DNAse treatment of several samples before RT-PCR analysis did not significantly affect the amount of NIS mRNA detected. Thus, it is unlikely that these specific technical issues affected the levels of NIS mRNA.

The variability of NIS mRNA expression demonstrated between different individuals may be related to differences in factors known to regulate NIS gene expression, including circulating and local concentrations of TSH, thyroid-stimulating immunoglobulins, cytokines, and iodine $(3,6,17,29)$. Furthermore, because the radioactive iodine uptake of these thyroid samples is not known, it is possible that these "normal" samples may have contained areas of autonomous function that may be associated with increased NIS expression. It is also possible that infiltration with nonNIS-expressing cells such as lymphocytes was present in the regions of normal tissue sampled from some individuals.

Although clinical records associated with these thyroid samples are not available for review, it is known that many of these patients were taking thyroid hormone replacement at the time of surgery. Some were on replacement doses for hypothyroidism, others were on suppressive doses of levothyroxine. Therefore, the NIS values we report for "normal" tissues reflect the amount of NIS present in grossly normal-appearing thyroid tissue with varying levels of TSH stimulation. An accurate assessment of NIS expression in "normal" thyroid tissue would require specific knowledge of the circulating TSH level at the time that a histologically verified sample of normal tissue was obtained, along with radioactive iodine imaging to rule out the presence of autonomous function. Because NIS expression is regulated by TSH, we would expect a much narrower range of NIS expression in normal samples exposed to similar levels of TSH stimulation.

Quantitative analysis of NIS and TG mRNA expression indicate that NIS is more influenced by TSH or thyroid-stimulating immunoglobulins than TG (23). Samples of hyperfunctioning thyroid glands demonstrated a marked increase in NIS expression but no significant change in TG or TSH-R expression within the same samples. Therefore, alterations in circulating TSH levels are likely to produce greater variations in NIS mRNA expression than in other thyroid-specific transcripts.
This wide range of NIS mRNA expression in normal tissues limits the relevance of comparing levels of NIS expression between groups of individuals. To eliminate between-subject variability, it is critical to compare NIS mRNA expression in paired samples obtained from individual subjects.

In summary, we have developed a highly sensitive and accurate real-time quantitative RT-PCR assay that demonstrates a marked reduction in NIS and TG mRNA expression in papillary thyroid cancers compared with normal adjacent tissue. We have also demonstrated that NIS mRNA is generally decreased in benign thyroid nodules relative to adjacent normal thyroid tissue and provide evidence that there is a wide variability in the expression of NIS mRNA in normal thyroid samples between different subjects. Our data support the contention that the decrease in iodine uptake characteristic of most malignant and benign thyroid nodules is due, at least in part, to a reduction in NIS mRNA levels within the thyroid cells. Further studies will be necessary to specifically correlate NIS mRNA expression with the activity of the functional sodium iodide symporter in these tumor samples.

Acknowledgments: The authors thank Ms. Phyllis Rhooms and Dr. Barbara Solomon for their contributions to this work.

\section{REFERENCES}

1. Dai G, Levy O, Carrasco N. Cloning and characterization of the thyroid iodide transporter. Nature 1996;379:458-60.

2. Smanik PA, Liu Q, Furminger TL, Ryu K, Xing S, Mazzaferri EL, et al. Cloning of the human sodium iodide symporter. Biochem Biophys Res Commun 1996;226:339-45.

3. Spitzweg C, Joba W, Morris JC, Heufelder AE. Regulation of sodium iodide symporter gene expression in FRTL-5 rat thyroid cells. Thyroid 1999;9:821-30.

4. Joba W, Spitzweg C, Schriever K, Heufelder AE. Analysis of human sodium/iodide symporter, thyroid transcription factor- 1, and paired-box-protein-8 gene expression in benign thyroid diseases. Thyroid 1999;9:455-66.

5. Ryu KY, Senokozlieff ME, Smanik PA, Wong MG, Siperstein $\mathrm{AE}$, Duh QY, et al. Development of reverse transcriptioncompetitive polymerase chain reaction method to quantitate the expression levels of human sodium iodide symporter. Thyroid 1999;9:405-9.

6. Ajjan RA, Watson PF, Findlay C, Metcalfe RA, Crisp M, Ludgate $\mathrm{M}$, et al. The sodium iodide symporter gene and its regulation by cytokines found in autoimmunity. J Endocrinol 1998;158:351-8.

7. Eskandari S, Loo DD, Dai G, Levy O, Wright EM, Carrasco N. Thyroid Na+/I- symporter. Mechanism, stoichiometry, and specificity. J Biol Chem 1997;272:27230-8.

8. Jhiang SM, Cho JY, Ryu KY, De Young BR, Smanik PA, McGaughy VR, et al. An immunohistochemical study of Na+/Isymporter in human thyroid tissues and salivary gland tissues. Endocrinology 1998;139:4416-9.

9. Castro MR, Bergert ER, Beito TG, McIver B, Goellner JR, Morris JC. Development of monoclonal antibodies against the human sodium iodide symporter: immunohistochemical 
characterization of this protein in thyroid cells. J Clin Endocrinol Metab 1999;84:2957-62.

10. Kawaguchi A, Ikeda M, Endo T, Kogai T, Miyazaki A, Onaya T. Transforming growth factor-betal suppresses thyrotropininduced $\mathrm{Na}+/ \mathrm{I}-$ symporter messenger RNA and protein levels in FRTL-5 rat thyroid cells. Thyroid 1997;7:789-94.

11. Kogai T, Endo T, Saito T, Miyazaki A, Kawaguchi A, Onaya T. Regulation by thyroid-stimulating hormone of sodium/iodide symporter gene expression and protein levels in FRTL-5 cells. Endocrinology 1997;138:2227-32.

12. Levy O, Dai G, Riedel C, Ginter CS, Paul EM, Lebowitz AN, et al. Characterization of the thyroid $\mathrm{Na}+/ \mathrm{I}-$ symporter with an anti-COOH terminus antibody. Proc Natl Acad Sci U S A 1997;94:5568-73.

13. Pekary AE, Hershman JM. Tumor necrosis factor, ceramide, transforming growth factor-betal, and aging reduce $\mathrm{Na}+/ \mathrm{I}-$ symporter messenger ribonucleic acid levels in FRTL-5 cells. Endocrinology 1998;139:703-12.

14. Schmutzler C, Winzer R, Meissner-Weigl J, Kohrle J. Retinoic acid increases sodium/iodide symporter mRNA levels in human thyroid cancer cell lines and suppresses expression of functional symporter in nontransformed FRTL-5 rat thyroid cells [published erratum appears in Biochem Biophys Res Commun 1998 May 19;246(2):562]. Biochem Biophys Res Commun 1997;240:832-8.

15. Ajjan RA, Findlay C, Metcalfe RA, Watson PF, Crisp M, Ludgate $\mathrm{M}$, et al. The modulation of the human sodium iodide symporter activity by Graves' disease sera. J Clin Endocrinol Metab 1998;83:1217-21.

16. Arturi F, Russo D, Schlumberger M, du Villard JA, Caillou B, Vigneri $\mathrm{P}$, et al. Iodide symporter gene expression in human thyroid tumors. J Clin Endocrinol Metab 1998;83:2493-6.

17. Ajjan RA, Kamaruddin NA, Crisp M, Watson PF, Ludgate M, Weetman AP. Regulation and tissue distribution of the human sodium iodide symporter gene. Clin Endocrinol (Oxf) 1998;49:517-23.

18. Trapasso F, Iuliano R, Chiefari E, Arturi F, Stella A, Filetti S, et al. Iodide symporter gene expression in normal and transformed rat thyroid cells. Eur J Endocrinol 1999;140:447-51.

19. Caillou B, Troalen F, Baudin E, Talbot M, Filetti S, Schlumberger $\mathrm{M}$, et al. $\mathrm{Na}+/ \mathrm{I}-$ symporter distribution in human thyroid tissues: an immunohistochemical study. J Clin Endocrinol Metab 1998;83:4102-6.
20. Saito T, Endo T, Kawaguchi A, Ikeda M; Nakazato M; Kogai $\mathrm{T}$, et al. Increased expression of the $\mathrm{Na}+/ \mathrm{I}-$ symporter in cultured human thyroid cells exposed to thyrotropin and in Graves' thyroid tissue. J Clin Endocrinol Metab 1997;82: 3331-6.

21. Saito T, Endo T, Kawaguchi A, Ikeda M, Katoh R, Kawaoi A, et al. Increased expression of the sodium/iodide symporter in papillary thyroid carcinomas. J Clin Invest 1998;101:1296300.

22. Smanik PA, Ryu KY, Theil KS, Mazzaferri EL, Jhiang SM. Expression, exon-intron organization, and chromosome mapping of the human sodium iodide symporter. Endocrinology 1997;138:3555-8.

23. Lazar V, Bidart JM, Caillou B, Mahe C, Lacroix L, Filetti S, et al. Expression of the $\mathrm{Na}+/ \mathrm{I}-$ symporter gene in human thyroid tumors: a comparison study with other thyroidspecific genes. J Clin Endocrinol Metab 1999;84:3228-34.

24. Hoang-Vu C, Dralle H, Scheumann G, Maenhaut C, Horn R, von zur Muhlen A, et al. Gene expression of differentiationand dedifferentiation markers in normal and malignant human thyroid tissues. Exp Clin Endocrinol 1992;100:51-6.

25. Elisei R, Pinchera A, Romei C, Gryczynska M, Pohl V, Maenhaut $\mathrm{C}$, et al. Expression of thyrotropin receptor (TSH-R), thyroglobulin, thyroperoxidase, and calcitonin messenger ribonucleic acids in thyroid carcinomas: evidence of TSH-R gene transcript in medullary histotype. J Clin Endocrinol Metab 1994;78:867-71.

26. Brabant G, Maenhaut C, Kohrle J, et al. Human thyrotropin receptor gene: expression in thyroid tumors and correlation to markers of thyroid differentiation and dedifferentiation. Mol Cell Endocrinol 1991;82:R7-12.

27. Park HJ, Kim JY, Park KY, Gong G, Hong SJ, Ahn IM. Expressions of human sodium iodide symporter mRNA in primary and metastatic papillary thyroid carcinomas. Thyroid 2000; 10:211-7.

28. Wingo ST, Ringel MD, Anderson JS, Patel AD, Lukes YD, Djuh YY, et al. Quantitative reverse transcription-PCR measurement of thyroglobulin mRNA in peripheral blood of healthy subjects. Clin Chem 1999;45:785-9.

29. Eng PH, Cardona GR, Fang SL, Previti M, Alex S, Carrasco N, et al. Escape from the acute Wolff-Chaikoff effect is associated with a decrease in thyroid sodium/iodide symporter messenger ribonucleic acid and protein. Endocrinology 1999;140:3404-10. 